\title{
ĐĂC ĐIỂM CHÂN RĂNG CỦA RĂNG CỐI LỚN THỨ NHẤT HÀM DƯớI TRÊN CONEBEAM CT TRONG ĐIỀU TRI NHA KHOA
}

\section{TÓM TẮT}

Mục tiêu: Xác định tỉ lệ xuất hiện răng cối lớn thứ nhất hàm dưới có hai chân, răng cối lớn thứ nhất hàm dưới có ba chân ở người Việt Nam khảo sát trên phim ConeBeam CT. Đối tượng và phương pháp: Nghiên cứu được thực hiện trên 166 bệnh nhân chụp phim CBCT theo chỉ định của bác sĩ tại Trung tâm CT nha khoa Nguyễn Trãi, Thành Phố Hồ Chí Minh, trong thời gian nghiên cứu từ tháng 10/2015 đến tháng 6/2016. Phim CBCT được chụp bằng máy chụp phim Picasso Trio (Ewoo Vatech, Korea) với các điều kiện và tư thế chuẩn của bệnh nhân cho chụp phim. Hình ảnh CBC̃T thu thập từ trung tâm CT đạt tiêu chuẩn chọn mẫu được quan sát trên máy tính màn hình phẳng 14 inches, độ phân giải 1366 x 768 pixel với phần mềm EzImplant $C D$ viewer. Ghi nhận vị trí răng (răng 36 và răng 46), sự xuất hiện của rằng cối lớn thứ nhất hàm dưới có hai chân, răng cối lớn thứ nhất hàm dưới có ba chân ở mỗi cá thể. Xác định số lượng chân răng của răng cối lớn thứ nhất hàm dưới bằng cách: trong mặt phẳng ngang (Axial), di chuyển các lát cắt trên thiết diên ngang của chân răng tữ đường nối men xêmăng đến chóp. Quan sát số lượng chân răng của răng cối lớn thứ nhất hàm dưới theo ba măt phẳng. Kết quả: $R C L$ thứ nhất hàm dưới có hai chân với tỉ lệ $83,7 \%$. Tỉ lệ người có $R C L$ thứ nhất hàm dưới có ba chân là $16,3 \%$. Sự xuất hiện của RCL thứ nhất hàm dưới có ba chân có thể đối xứng hoặc không đối xứng. Không có sự khác biệt về giới, vị trí xuất hiện liên quan đến tỉ lệ RCL thứ nhất hàm dưới có ba chân. Kết luận: Tỉ lệ răng cối lớn thứ nhất hàm dưới trên ConeBeam CT có hai chân chiếm đa số

Tư khóa: chân răng, răng cối lớn thứ nhất hàm dưới, ConeBeam CT.

Viết tắt: RCL1 HD: răng cối lớn thứ nhất hàm dưới; CBCT : ConeBeam CT

\section{SUMMARY \\ ROOT CHARACTERISTICS OF THE FIRST LOWER MOLARS ON CONEBEAM CT IN DENTAL TREATMENT}

Objectives: The aim of the study is to determine the prevalence of the first lower molars that have two roots or three roots (two main roots and additional distal-lingual root) in Vietnamese on ConeBeam CT. Subjects and methods:The study was conducted on 166 patients who had exposured using CBCT indicated by dentists in Nguyen Trai Dental CT Central, HoChiMinh City, from October 2015 to June 2016. The

${ }^{1}$ Đại học Y Dước TP.HCM

Chịu trách nhiệm chính: Huỳnh Kim Khang

Email: kimkhanghuynh@yahoo.com

Ngày nhận bài: $8 / 3 / 2021$

Ngày phản biên khoa học: 1/4/2021

Ngày duyệt bài: 2/5/2021

\section{Huỳnh Kim Khang ${ }^{1}$, Phạm Văn Khoa ${ }^{1}$}

CBCT digital images were captures using Picasso Trio (Ewoo Vatech, Korea) with the standard conditions and postures of patients. CBCT digital images were displayed on the 14 inches flat monitor, at $1366 \times 768$ pixel resolution with EzImplant $C D$ viewer software. The first lower molars with two roots and three roots were recorded. The number of roots of the first lower molars was determined by moving cross-sectional slices from enamel-cement junction to the apex. The number of roots of the first lower molar was observed in three planes. Results: The first lower molars with two roots were at $83.7 \%$. The rate of person who had the first lower molars with three roots was $16.3 \%$. The situation of the first lower molars with three roots can be symmetrical or asymmetrical. There was no differences about sex, positions of the first lower molars with three roots. Conclusion: The prevalences of two roots of the first lower molars accounts for the largest portion.

Keywords: Root, first lower molar, ConeBeam CT.

\section{I. ĐĂT VẤN ĐỀ}

Răng cối lớn thứ nhất hàm dưới là một trong những răng vĩnh viễn đầu tiên mọc lên trong miệng, vào khoảng sáu tuổi, đánh dấu sự khởi đầu của bộ răng hỗn hợp. Răng cối lớn thứ nhất hàm dưới mang đặc điểm cơ bản đặc trưng cho các răng cối lớn, có vai trò quan trọng trong việc nhai nghiên thức ăn và giữ kích thước tầng dưới mặt.

Trên lâm sàng, răng cối lớn thứ nhất hàm dưới là một trong các răng có tỉ lệ sâu mất trám cao nhất, kể cả ở lứa tuổi còn trẻ [0]. Những hiểu biết về hình thái chân răng, số lượng và vị trí ống tủy rất quan trọng và cần thiết trong quá trình điều trị nha khoa như điều trị nôi nha, phẫu thuật cắt chóp, nhổ răng. Răng cối lớn thứ nhất hàm dưới có hình thái chân răng và ống tủy khá phức tạp, đa số có hai chân răng và ba ống tủy [2]. Tuy nhiên, ở các chủng tộc Mongoloid, tỉ lệ răng cối lớn thứ nhất hàm dưới có ba chân (thêm một chân ở phía xa trong) tương đối cao, chiếm khoảng $20 \%$. Răng thường được điều trị nôi nha nhiêu nhất là răng cối lớn thứ nhất hàm dưới [8], vì đây là răng vĩnh viễn mọc đâu tiên trên cung hàm và có hệ thống ống tủy phức tạp và cũng là răng có chức năng ăn nhai quan trọng cần được bảo tồn nhất. Số lượng ống tủy thay đổi khi răng cối lớn thứ nhất hàm dưới có ba chân. Do đó, việc nghiên cứu về hình thái chân răng, số lượng và vị trí ống tủy của răng cối lớn thứ nhất hàm dưới sẽ giúp các nhà lâm sàng có thêm cơ sở khi điều trị nội nha răng này 
và tránh được sai lầm bỏ sót ống tủy, một nguyên nhân thường gặp gây thất bại trong điều trị nội nha.

Đã có nhiều nghiên cứu trên thế giới tập trung khảo sát những đăc điểm giải phẩu vùng răng cối lớn thứ nhất hàm dưới về hình thái và số lượng chân răng với mong muốn tạo ra một bộ cơ sở dữ liệu về vùng giải phẫu quan trọng này, nhằm giúp các nhà lâm sàng đưa ra kế hoạch điều trị tối ưu nhất cũng như dự đoán được tiên lượng trước khi tiến hành điều trị phục hồi và bảo tồn. Trong đó, nhiều nghiên cứu sử dụng phương tiện chủ yếu là Phim cắt lớp điện toán chùm tia hình nón (ConeBeam CT - CBCT). Đây là công cụ tốt nhất hiện nay để khảo sát mô cứng vùng răng hàm mặt, theo ba chiều trong không gian với ưu điểm cho hình ảnh rõ nét, giảm thiểu độ biến dạng và kỹ thuật ít xâm lấn. Phim CBCT có thể cung cấp thông tin toàn diện về số lượng, vị trí chân răng và đặc biệt là giải phẫu hê thống ống tủy, kích thước các vách xương ổ răng, tương quan giữa các chóp răng với ống răng dưới của răng cối lớn thứ nhất hàm dưới. Muc tiêu của nghiên cứu là nhằm xác đinh tỉ lệ xuất hiện răng cối lớn thứ nhất hàm dưới có hai chân, răng cối lớn thứ nhất hàm dưới có ba chân ở người Việt Nam khảo sát trên phim CBCT.

\section{II. ĐỐI TƯợNG VÀ PHƯƠNG PHÁP NGHIÊN CỨU}

2.1. Thiết kế nghiên cứu: Nghiên cứu cắt ngang mô tả

2.2. Mẫu nghiên cứu: Gồm phim $C B C T$ xương hàm dưới của các cá thể thỏa điều kiện chon mẫu được chup theo chỉ đinh của bác sĩ tai Trung tâm CT nha khoa Nguyễn Trãi - địa chỉ 132 An Bình - Quận 5 - thành phố Hồ Chí Minh, trong thời gian nghiên cứu từ tháng 10/2015 đến tháng 6/2016. Dưa vào tî lệ răng cối lớn thứ nhất hàm dưới có ba chân ở người Thái Lan (nghiên cứu của Gulabivala và c.s. (2002) [5]) p $=0,127$, trong nghiên cứu này tính được cỡ mẫu tương ứng là $n=166$. Công thức tính cỡ mẫu $n=$ $\left[Z^{2}{ }_{1-a / 2} p(1-p) / d^{2}\right]$ (trong đó $a=0,02$ : xác suất sai lầm loại I; $Z_{1-a / 2}=2,32$ : trị số phân phối chuẩn; $\mathrm{d}=0,06$ : độ chính xác mong muốn). Hình ảnh CBCT xương hàm dưới của người Viêt Nam có đủ hai răng cối lớn thứ nhất hàm dưới (răng 36 và răng 46). Phim CBCT được chụp bằng máy chụp phim Picasso Trio (Ewoo Vatech, Korea) với các điều kiên và tư thế chuẩn của bênh nhân cho chụp phim (chiều dày mỗi lát cắt $0,1 \mathrm{~mm}$; FOV: $8 \times 5 \mathrm{~cm}$; thời gian chụp: 15 giây; thời gian dựng ảnh 29 giây). Răng cối lớn thứ nhất hàm dưới thỏa điều kiện: răng phát triển đầy đủ và đã đóng chóp. Các răng khảo sát không có bất thường về vị trí, không có tiêu ngót chân răng, bệnh lý nha chu, nhiễm trùng chóp ảnh hưởng đến viêc đánh giá vách xương, ông thần kinh răng dưới; răng không có điều trị nội nha, thân và chân răng không bị các tổn thương (sâu răng, mòn răng, nứt) hay miếng trám lớn ảnh hưởng đến hốc tủy, có đầy đủ thông tin về năm sinh, giới tính, ngày chụp; phim đạt chuẩn, hình ảnh rõ nét, độ sáng đủ, độ tương phản rõ.

Hình ảnh CBCT thu thâp từ trung tâm CT đat tiêu chuẩn chọn mẫu được quan sát trên máy tính màn hình phẳng 14 inch, độ phân giải 1366 x 768 pixel với phần mềm EzImplant $C D$ viewer. Quan sát trên phim và ghi nhận kết quả. Ghi nhân mã số phim, giới tính, tuổi, ngày chụ, tên bênh nhân (viết tắt) vào phiếu thu thập. Khi tiến hành đo phần thông tin của bệnh nhân trên phim và trên phiếu thu thấp kết quả được che đi. Phim cần đo được chuyển về chế độ xem gốc ban đầu (thao tác Reset all), với độ phóng đại 1,5 lần. Ghi nhận vị trí răng (răng 36 và răng 46), sự xuất hiện của răng cối lớn thứ nhất hàm dưới có hai chân, răng cối lớn thứ nhất hàm dưới có ba chân ở mối cá thể. Xác định số lượng chân răng của răng cối lớn thứ nhất hàm dưới bằng cách: trong mặt phẳng ngang (Axial), di chuyển các lát cắt trên thiết diện ngang của chân răng từ đường nối men xê-măng đến chóp. Quan sát số lượng chân răng của răng cối lớn thứ nhất hàm dưới theo ba mặt phẳng .

2.3. Vấn đề $y$ đức. Nghiên cứu của chúng tôi không vi pham y đức vì; nghiên cứu chỉ thu thập phim của bệnh nhân có chỉ định chụp CBCT tai phòng CT Nguyễn Trãi theo chỉ định của bác sĩ điều trị; các thông tin của bênh nhân được bảo mật hoàn toàn và chỉ sử dung cho mục đích nghiên cứu; nghiên cứu được thông qua bởi Hội đồng đạo đức trong nghiên cứu y sinh hoc ĐHYD Tp. Hồ Chí Minh (tháng 10/2015).

\section{KẾT QUẢ NGHIÊN CỨU}

\section{1. Đặc điểm mẫu nghiên cứu}

Mẫu nghiên cứu gồm phim CBCT của 166 người, trong đó nam chiếm $56,6 \%$ và nữ chiếm 43,4\% (Bảng 1). Xét theo nhóm tuổi có 83 đối tượng từ 30 - 50 tuổi, cao hơn gấp đôi so với đối tượng dưới 30 tuổi (41 người) và trên 50 tuổi (42 người).

Bảng 1. Đặc điểm mẫu nghiên cứu.

\begin{tabular}{|c|c|c|c|}
\hline \multirow{2}{*}{ Nhóm tuổi } & \multicolumn{3}{|c|}{ Mầu nghiên cứu (n = 166) } \\
\cline { 2 - 4 } & Nam n(\%) & Nữ n(\%) & Tống n \\
\hline Từ 18-dưới30 & $16(17)$ & $25(34,7)$ & 41 \\
\hline Từ 30-50 & $42(44,7)$ & $41(56,9)$ & 83 \\
\hline
\end{tabular}




\begin{tabular}{|c|c|c|c|}
\hline Trên 50 & $36(38,3)$ & $6(8,3)$ & 42 \\
\hline Toàn mâu & 94 & 72 & 166 \\
\hline
\end{tabular}

Mối đối tượng trong mẫu nghiên cứu được khảo sát 2 răng cối lớn thứ nhất hàm dưới gồm răng 36 và răng 46, tổng cộng có 332 răng được nghiên cứu.

3.2. Đắc điểm sự phân bố của răng côii lớn thứ nhất hàm dưới có hai chân và răng cối lớn thứ nhất hàm dưới có ba chân

- Tỉ lệ phân bố của răng cối lớn thứ nhất hàm dưới có hai chân và răng cối lớn thứ nhất hàm dưới có ba chân

Sau khi tiến hành khảo sát hình ảnh $\mathrm{CBCT}$ của 166người nêu trên với 332 răng cối lớn thứ nhất hàm dưới, chúng tôi nhận thấy phần lớn (87,7\%, 291/332) các răng cối lớn thứ nhất hàm dưới có hai chân. Tổng số răng cối lớn thứ nhất hàm dưới ở 166người là 332 răng, trong đó có 291 răng cối lớn thứ nhất hàm dưới có hai chân, 41 răng cối lớn thứ nhất hàm dưới có ba chân. Tî lệ răng cối lớn thứ nhất hàm dưới có ba chân tính theo số răng là 12,3\% (bảng 2).

Trong 166người có 27 người có ít nhất một răng cối lớn thứ nhất hàm dưới có ba chân, 139 người còn lại có răng cối lớn thứ nhất hàm dưới hai chân ở cả hai bên phần hàm. Như vậy tỉ lệ răng cối lớn thứ nhất hàm dưới có ba chân ở người Việt là 16,3\%.

Bảng 2. Tần số và tỉ lệ răng cối lớn thứ nhất hàm dưới có hai chân và răng cối lớn thứ nhất hàm dưới có ba châncủa 166 người.

\begin{tabular}{|c|c|c|c|c|c|c|}
\hline & \multicolumn{2}{|c|}{ RCL1 HD hai chân } & \multicolumn{2}{c|}{ RCL1 HD ba chân } & \multicolumn{2}{c|}{ Tống } \\
\cline { 2 - 7 } & $\mathbf{n}$ & $\mathbf{( \% )}$ & $\mathbf{n}$ & $\mathbf{( \% )}$ & $\mathbf{n}$ & $\mathbf{( \% )}$ \\
\hline Người & 139 & 83,7 & 27 & 16,3 & 166 & 100 \\
\hline Răng & 291 & 87,7 & 41 & 12,3 & 332 & 100 \\
\hline
\end{tabular}

- Sự phân bố của răng cối lớn thứ nhất hàm dưới có hai chân và răng cối lớn thứ nhất hàm dưới có ba chân theo vị trí

Tî lệ người có cả hai răng cối lớn thứ nhất hàm dưới có ba chân ở cả hai bên hàm là $8,5 \%$. Số người chỉ có răng cối lớn thứ nhất hàm dưới có ba chân ở một bên hàm chiếm 7,8 \% trong số 166 người. Trong đó, tỉ lệ người chỉ có một răng cối lớn thứ nhất hàm dưới có ba chân ở bển phải chiếm $6,6 \%$, cao hơn so với tỉ lệ người chỉ có một răng cối lớn thứ nhất hàm dưới có ba chân ở bên trái là 1,2\% (bảng 3).

Trong 332 răng cối lớn thứ nhất hàm dưới hai bên của 166 người này, tỉ lệ răng cối lớn thứ nhất hàm dưới có ba chân ở bên trái là 9,7\%, tỉ lệ này ở bên phải là $15,1 \%$. Tuy nhiên sự phân bố của răng cối lớn thứ nhất hàm dưới có ba chân theo vị trí khác biệt không có ý nghĩa (kiểm định Chi bình phương $p=0,182$ ).

Bảng 3. Sự phân bố theo vị trí răng cối lớn thứ nhất hàm dưới có ba chân của 166 người.

\begin{tabular}{|c|c|c|}
\hline & $\begin{array}{c}\text { Nhóm RCL1 } \\
\text { HD hai chân }\end{array}$ & $\begin{array}{c}\text { Nhóm RCL1 } \\
\text { HD ba chân }\end{array}$ \\
\hline Hai bên & $139(83,7 \%)$ & $14(8,5 \%)$ \\
\hline Một bên & & \\
\hline Trái & $11(6,6 \%)$ & $2(1,2 \%)$ \\
\hline Phải & $2(1,2 \%)$ & $11(6,6 \%)$ \\
\hline
\end{tabular}

Trong 27 người có ít nhất một răng cối lớn thứ nhất hàm dưới có ba chân, tỉ lệ người có răng cối lớn thứ nhất hàm dưới có ba chân ở cả hai bên và tỉ lệ người có răng cối lớn thứ nhất hàm dưới có ba chân ở một bên xấp xỉ 1:1 (bảng 4). Như vậy sự xuất hiện của răng cối lớn thứ nhất hàm dưới có ba chẩn có thể đối xứng hoặc

không đối xứng (hình 1 và 2 ).

Bảng 4. Sự phân bố theo vị trí của răng cối lớn thứ nhất hàm dưới có ba chân ở 27 người có ít nhất một răng cối lớn thứ nhất hàm dưới có ba chân.

\begin{tabular}{|c|c|c|c|c|c|}
\hline & \multirow{2}{*}{$\begin{array}{c}\text { RCL1 } \\
\text { HD ba } \\
\text { chân ha } \\
\text { bên }\end{array}$} & \multicolumn{3}{|c|}{$\begin{array}{c}\text { RCL1 HD ba chân } \\
\text { một bên }\end{array}$} & \multirow{2}{*}{ Tổng } \\
\hline & & $\begin{array}{c}\text { Trái } \\
\text { (R36) }\end{array}$ & $\begin{array}{l}\text { Phải } \\
\text { (R46) }\end{array}$ & Tổng & \\
\hline n (người) & 14 & 2 & 11 & 13 & 27 \\
\hline Tỉ lệ (\%) & 51,9 & 7,4 & 40,7 & 48,1 & 100 \\
\hline
\end{tabular}

- Sư phân bố của răng cối lớn thứ nhất hàm dưới có hai chân và răng cối lớn thứ nhất hàm dưới có ba chân theo giới. Trong 166 người tham gia vào nghiên cứu, có 94 nam và 72 nữ. Tỉ lệ răng cối lớn thứ nhất hàm dưới hai chân ở nữ là $87,5 \%$ cao hơn ở nam là $80,9 \%$, tuy nhiên sự khác biệt này không có có ý nghĩa thống kê $(p=0,482)$. Tỉ lệ nam có răng cối lớn thứ nhất hàm dưới có ba chân là 19,1\%, cao hơn so với tỉ lệ này ở nữ là $12,5 \%$ (bảng 5 ).

Bảng 5. Sự phân bố răng cối lớn thứ nhất hàm dưới theo giới tính.

\begin{tabular}{|c|c|c|c|c|}
\hline & \multicolumn{2}{|c|}{ Nam } & \multicolumn{2}{c|}{ Nũ̃ } \\
\hline & $\mathbf{n}$ & $\mathbf{\%}$ & $\mathbf{n}$ & $\mathbf{\%}$ \\
\hline RCL1 HD hai chân & 76 & 80,9 & 63 & 87,5 \\
\hline RCL1 HD ba chân & 18 & 19,1 & 9 & 12,5 \\
\hline Tống & 94 & 100 & 72 & 100 \\
\hline
\end{tabular}

Đặc điểm răng cối lớn thứ nhất hàm dưới có ba chân xuất hiện ở nam nhiều hơn nữ. Tuy nhiên, sự phân bố này theo giới tính khác biệt không có ý nghĩa thống kê $(p=0,293)$. Bảng 6 cho thấy tỷ lệ phân bố răng cối lớn thứ nhất hàm dưới theo giới tính và theo vị trí. 


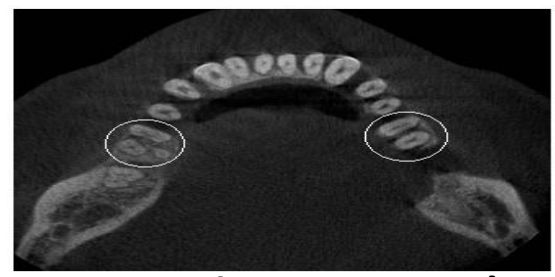

Hình 1. Lát cắt trên măt phẳng ngang (Axial): BN Nguyễn C., nam, 47 tuôii, có RCL thứ nhất $H D$ ba chân bên $(P)$ và $R C L$ thứ nhất $H D$ hai chân bên (T).

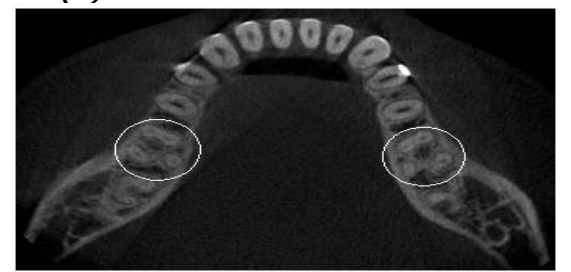

Hình 2. Lát cắt trên mặt phẳng ngang

(Axial): BN Vỗ Thi Trúc L., nũ̃, 31 tuôii, có RCL thứ nhất HD ba chân ở hai bên.

Bảng 6. Sự phân bố răng cối lớn thứ nhất hàm dưới có ba chân theo giới tính và theo vi trí.

\begin{tabular}{|c|c|c|c|}
\hline & $\begin{array}{c}\text { Nam } \\
(n=94)\end{array}$ & $\begin{array}{c}\text { Nữ } \\
(n=72)\end{array}$ & $\begin{array}{c}\text { Tống } \\
(n=166)\end{array}$ \\
\hline Hai bên & $8(4,9 \%)$ & $6(3,6 \%)$ & $14(8,5 \%)$ \\
\hline Một bên & $10(6,0 \%)$ & $3(1,8 \%)$ & $13(7,8 \%)$ \\
\hline Trái & $2(1,2 \%)$ & $0(0,0 \%)$ & $2(1,2 \%)$ \\
\hline Phải & $8(4,8 \%)$ & $2(1,8 \%)$ & $11(6,6 \%)$ \\
\hline
\end{tabular}

\section{BÀN LUÂ̂N}

Răng cối lớn thứ nhất hàm dưới có nhiều biến thể về giải phẫu. Một trong những biến thể chính của răng này là sự xuất hiện thêm một chân phụ, gọi là chân xa trong. Chân này được gọi bằng thuật ngữ "radix entomolaris", có nghĩa là một chân phụ, "mọc" ra từ phía trong của chân xa. Trong nghiên cứu này, chúng tôi ghi nhận được tỉ lệ xuất hiện của $\mathrm{RCL}$ thứ nhất hàm dưới có hai chân là $87,7 \%$ và tỉ lệ RCL thứ nhất hàm dưới có ba chân ở người Việt là $12,3 \%$. Chúng tôi không ghi nhâan được xự xuất hiện của RCL thứ nhất hàm dưới chỉ có một chân dạng hình nón hay $\mathrm{RCL}$ thứ nhất hàm dưới một chân với ống tủy hình $C$ vì đây là những biến thể của $R C L$ thứ nhất hàm dưới khá hiếm gặp. Kết quả này cao tương tự các nghiên cứu thực hiện trên dân số ở một số nước trong khu vực như Thái Lan 12,7\%, Ấn Độ 13,3\%, Nhật Bản 11,4\% [5]. Tuy nhiên tỉ lệ này vấn là khá cao so với các nước ở các châu lục khác như Ai Cập chỉ có $0,7 \%$, Ả Rập 2,3\%, Thổ Nhĩ Kỳ chỉ có 2,4\%, Mĩ (người Mĩ gốc châu Âu) là $2,2 \%$, Anh là $3,3 \%$, Đức chỉ có $0,7 \%$ [6]. Như vậy, tần suất xuất hiện RCL thứ nhất hàm dưới có ba chân thay đổi khác nhau theo chủng tộc, răng cối lớn thứ nhất hàm dưới có ba chân gặp nhiều ở người Mongoloid, ít gặp ở người da trắng và người Châu Phi.

Nguồn gốc của sự xuất hiện RCL thứ nhất hàm dưới ba chân vẫn chưa rõ ràng. Curzon (1974) [4] cho rằng sự xuất hiện RCL thứ nhất hàm dưới ba chân có thể là đặc điểm di truyền trội vì tác giả thực hiện hai nghiên cứu ở người Eskimo và người Eskimo lai người châu Âu thì tỉ lệ này đều bằng nhau. Một số nghiên cứu gần đây còn cho thấy sự xuất hiện chân xa trong ở các răng cối lớn thứ hai hàm dưới kết hợp với chân răng có ống tủy hình $C$ của các răng này. Các tác giả giải thích sự hiện diện của chân răng phụ này là do sự hình thành ống tủy hình $C$ của chẩn răng không liên tục, tạo ra những đoạn rời rạc dẫn đến sự hình thành một chân răng riêng rể. Tuy nhiên cần nhiều nghiên cứu hơn nữa để làm sáng tỏ nguồn gốc của sự hình thành chân răng thứ ba này là do yếu tố gen hay yếu tố khác quyết định. Nhưng tất cả các nghiên cứu đều khẳng định biến thể răng cối lớn thứ nhất hàm dưới có ba chân liên quan với yếu tố chủng tộc.

Nhìn chung, răng cối lớn thứ nhất hàm dưới có ba chân ở người Việt chiếm tỉ lệ cao tương tự các chủng tộc Mongoloid khác. Chúng tôi chọn mẫu là các cá thể còn đủ hai răng cối lớn thứ nhất hàm dưới để khảo sát sự phân bố theo vị trí của RCL thứ nhất hàm dưới hai chân và $R C L$ thứ nhất hàm dưới ba chân. Trong 332 răng cối lớn thứ nhất hàm dưới của 166 người, phần lớn (87,7\%, 291/332) các răng cối lớn thứ nhất hàm dưới có hai chân. Tỉ lệ răng cối lớn thứ nhất hàm dưới hai chân ở nữ $(87,5 \%, 63 / 72)$ cao hơn ở nam $(80,9 \%, 76 / 94)$, sự khác biệt không có có ý nghĩa thống kê.

Trong 166 người có 27 người có ít nhất một răng cối lớn thứ nhất hàm dưới có ba chân. Trong đó, tỉ lệ người có cả hai răng cối lớn thứ nhất hàm dưới có ba chân là $8,5 \%(14 / 166)$ và tỉ lệ người chỉ có răng cối lớn thứ nhất hàm dưới ba chân ở một bên là 7,8\% (13/166). Tỉ lệ người có răng cối lớn thứ nhất hàm dưới ba chân ở bên trái là $9,7 \%$ và ở bên phải là $15,1 \%$. Tỉ lệ nam có răng cối lớn thứ nhất hàm dưới ba chân là $19,1 \%$ và tỉ lệ nữ có răng cối lớn thứ nhất hàm dưới ba chân là $12,5 \%$. Tuy nhiên, các sự khác biệt này đều không có ý nghĩa thống kê.

Trong nghiên cứu của chúng tôi, sự phân bố của răng cối lớn thứ nhất hàm dưới ba chân ở nam và nữ là như nhau, tương đồng với nghiên cứu của Schafer và c.s. (2009) [6],. Các nghiên cứu chỉ ra rằng không có sự khác biệt về tỉ lệ RCL thứ nhất hàm dưới có ba chân theo giới tính. 
Về vị trí xuất hiện của răng cối lớn thứ nhất hàm dưới ba chân, kết quả nghiên cứu của chúng tôi gần giống kết quả của một số nghiên cứu khác cho rằng $\mathrm{RCL}$ thứ nhất hàm dưới ba chân xuất hiện ở bên phải nhiều hơn bên trái. Sự khác biệt về kết quả này có thể được giải thích do sự khác nhau trong cách chọn mẫu và phương pháp nghiên cứu tùy theo từng tác giả.

Các nhà lâm sàng cần lưu ý khi điều trị nội nha chân răng xa trong ở $\mathrm{RCL}$ thứ nhất hàm dưới để giảm nguy cơ đi sai hướng, tạo khấc, thủng ống tủy, gãy dụng cụ và đưa dụng cụ đi quá chóp trong quá trình sửa soạn ống tủy.

Lối mở vào tủy hình tam giác thường dùng cho RCL thứ nhất hàm dưới cần phải được biến đổi thành lối vào tủy có dạng hình thang để có thể định vị ống tủy xa trong và tất cả những ống tủy hiện diện trên RCL thứ nhất hàm dưới có ba chân.

Thường phải tạo đường vào trơn tru (glide path) từ trâm số nhỏ nhất, chọn trâm có độ đàn hồi cao như trâm NiTi và sửa soạn thật chậm rãi, cẩn thận. Nếu vội vàng thì nguy cơ cao sẽ bị lạc đường, tạo khấc, tắc ống tủy và thậm chí là gã̃y dụng cụ ở dưới đoạn gập góc, khả năng lấy ra được rất thấp và để lách qua đoạn trâm gãy cũng rất khó. Ống tủy cong một phần hoặc cong toàn bộ của chân răng xa trong này làm tăng nguy cơ gãy trâm ở bất kỳ đoạn nào của ống tủy trong quá trình sửa soạn ống tủy.

\section{KẾT LUẬN}

Tỉ lệ răng cối lớn thứ nhất hàm dưới trên ConeBeam CT có hai chân chiếm đa số. Đây là đặc điểm làm cơ sở cho các thầy thuốc trong điều trị nội nha.

\section{TÀI LIỆU THAM KHẢO}

1. Nguyễn Cẩn, Ngô Đồng Khanh. (2007), "Phân tích dịch tễ bệnh sâu răng và nha chu ở Việt Nam". Tạp chí Y học Thành phố Hô Chí Minh, 11(3), 144-149.

2. de Pablo O. V., Estevez R., Peix Sanchez M., et al. (2010), "Root anatomy and canal configuration of the permanent mandibular first molar: a systematic review". J Endod, 36(12), 1919-1931.

3. Chen Y. C., Lee Y. Y., Pai S. F., et al. (2009) "The morphologic characteristics of the distolingual roots of mandibular first molars in a Taiwanese population". J Endod, 35(5), 643-645.

4. Curzon M. E. (1974), "Miscegenation and the prevalence of three-rooted mandibular first molars in the Baffin Eskimo". Community Dent Oral Epidemiol, 2(3), 130-131.

5. Gulabivala K., Opasanon A., Ng Y. L., et al. (2002), "Root and canal morphology of Thai mandibular molars". Int Endod J, 35(1), 56-62.

6. Schafer E., Breuer D. ,Janzen S. (2009), "The prevalence of three-rooted mandibular permanent first molars in a German population". J Endod, 35(2), 202-205.

7. Ishii Namiko, Sakuma Ayaka, Makino Yohsuke, et al. (2016), "Incidence of threerooted mandibular first molars among contemporary Japanese individuals determined using multidetector computed tomography". Legal Medicine, 22, 9-12.

8. Serene T. P. ,Spolsky V. W. (1981), "Frequency of endodontic therapy in a dental school setting". J Endod, 7(8), 385-387.

\title{
HIÊ̂U QUẢ ĐIỀU TRI TRIÊTT CĂN BẰNG XẠ TRI ĐIỀU BIẾN LIỀU ĐồnG THỜI VỚI HÓA CHẤT PHÁC ĐỒ FOLFOX CHO BỆNH NHÂN UNG THƯ THỰC QUẢN
}

\author{
Dương Thùy Linh'1, Phạm Thị Mai ${ }^{1}$, Trần Văn Tôn ${ }^{1}$, \\ Lại Thị Định ${ }^{1}$, Nguyễn Vắn Ba ${ }^{1}$, Trần Viết Tiến ${ }^{1}$
}

\section{TÓM TẮT}

Mục tiêu: Đánh giá hiệu quả xạ trị điều biến liều hóa xạ đồng thời với phác đồ FOLFƠx điều trịtriệt căn ung thư thực quản. Đối tượng và phương pháp: Nghiên cứu mô tả tiến cứu 32 bệnh nhân ung thư thực quản giai đoạn cT2-4N+M0 hóa xa trị đông thời triệt căn với kĩ thuật xạ trị điều biến liều tại khoa Vật lý xạ trị - Trung tẩm Üng bướu - Bệnh viện Quân Y

${ }^{1}$ Bệnh viện Quân y 103

Chịu trách nhiệm chính: Dương Thùy Linh

Email: bsduonglinh103@gmail.com

Ngày nhận bài: 7/3/2021

Ngày phản biên khoa học: 4/4/2021

Ngày duyệt bài: 2/5/2021
103- Hoc viên Quân $Y$ từ T1/2018 - T6/2020. Kết quả: Bểnh nhân chủ yếu là nam giới, tuổi hay gặp 40 - 59 tuổi. Mô bênh học $100 \%$ là ung thư biểu mồ vảy, $50 \%$ là ung thư biểu mô vảy biệt hóa vừa. Cách phân liều: $66 \mathrm{~Gy} / 30 \mathrm{fx}$ chiếm tỉ lệ $25 \%, 60 \mathrm{~Gy} / 28 \mathrm{fx}$ chiếm tỉ lê $75 \%$. Hóa chất phác đồ FOLFOX đủ liều chiếm tỉ lệ $71,9 \%$, giảm liều chiếm tỉ lệ $28,1 \%$. Đánh giá đáp ứng trên $\mathrm{CT}$ : đáp ứng hoàn toàn chiếm $56,2 \%$, đáp ứng một phần chiếm tỉ lệ $34,4 \%$, không đáp ứng 9,4\%. Biến chứng trên hệ tạo máu: thiếu máu(34,4\%), giảm bach câu $(21,9 \%)$, giảm tiểu cầu $(15,6 \%)$. Biến chứng viêm thực quản $90,6 \%$, viêm da $56,2 \%$ chủ yếu độ 1 , độ 2. Kết luân: Điều trị triệt căn ung thư thực quản bắng phác đồ hóa xạ trị đồng thời với kĩ thuật xạ trị điều biến liêu kết hợp hóa chất phác đồ FOLFOX cho kết quả đáp ứng tốt, tỉ lệ độc tính trong giới hạn chấp 